Psychological Medicine, 2002, 32, 191-194. (C) 2002 Cambridge University Press

DOI: $10.1017 /$ S0033291701004962 Printed in the United Kingdom

EDITORIAL

\title{
The clinical epidemiology of hysteria: vanishingly rare, or just vanishing ${ }^{1}$
}

Vanish 1. intr. To disappear from sight or become invisible, esp. in a rapid and mysterious way (Shorter Oxford English Dictionary, 1972).

There is a well-known view that hysteria has virtually disappeared in the Western world. There are two versions of this argument: one is that there was never a clinical disorder that coincided with the diagnosis, and hysteria has now been reconstructed as something else (e.g. Micale, 1993). The other is that hysteria did exist but has now become much rarer than it was (most famously, Veith, 1965). According to this view, hysteria is to be found in patients from developing countries, but in Western countries it is 'virtually a historical curiosity' (BMJ, 1976). It is the latter view that is - in our experience - most commonly held by our colleagues in general psychiatry. Yet, this opinion is not shared by those who are involved in the clinical care of patients with neurological disorders: "to a psychiatrist who sees patients on the medical and surgical services of a general hospital, it appears that hysteria remains a rather common phenomenon' (Brownsberger, 1966). A number of descriptions from liaison psychiatry services support this opinion (Akagi \& House, 2001). There are good reasons why it might be difficult to judge just how common (or rare) hysteria really is. Epidemiology depends on reliable case definition, case ascertainment and selection of a suitable population to study (Neugebauer et al. 1980), and each of these poses problems in the study of hysterical disorders.

\section{BARRIERS TO STUDYING THE EPIDEMIOLOGY OF HYSTERIA}

First, there is the well-known problem with case definition - arising from inconsistent use of terminology and changes in diagnostic practice. Hysteria has referred to an underlying disposition manifest as emotional instability, sexual dysfunction, relationship difficulties or suggestibility (Satowa, 1979). It has been used to ascribe aetiology - to describe physical illnesses which have a psychological provocation, and which develop as a means of adapting to (or defending against) that provocation. And it has been used descriptively for those with the condition now termed conversion disorder (in DSM-IV (American Psychiatric Association, 1994)) or dissociative (conversion) disorder (in ICD-10 (World health Organization, 1992)), as well as to describe the very different presentation of somatization disorder or Briquet's syndrome.

In the latter (descriptive) usage the diagnosis depends on the presence of a physical syndrome, exclusion of organic cause to account for the syndrome and some evidence of psychological factors in its cause. Malingering and factitious disorders, where the symptoms are produced or feigned intentionally, are excluded. The difficulties with this approach include having to base diagnosis on the absence of disease; the absence of a robust test for psychological causes, and the uncertainty inherent in excluding intentional symptom production. The result will inevitably be diagnostic errors and variations in practice, which will affect estimates of the frequency of the condition (Wessely, 2001).

Secondly there is a problem of case ascertainment. In Western practice hysteria rarely presents

${ }^{1}$ Addressforcorrespondence:ProfessorAllanHouse,AcademicUnitofPsychiatryandBehaviouralSciences,15HydeTerrace,Leeds LS2 9LT. 
to psychiatrists in the first instance, and even those diagnosed with the condition by others may not be referred to a psychiatrist. In Watts' general practice study (Watts et al. 1964), at least $40 \%$ of the patients were not seen by a psychiatrist. Psychiatric referral from A\&E is similarly limited (Anstee, 1972a; Dula \& DeNaples, 1995). We do not know how common it is for people with conversion disorders to escape referral to any specialist, but it is possible that a proportion - perhaps especially those whose symptoms are transient-will not present in secondary health care. Therefore, comprehensive case ascertainment will require a system that is not dependent on referrals to specialists in neurology or psychiatry, but on a prospective search for cases.

Case ascertainment also requires an accurate case-finding method. The need for exclusion of an organic cause makes a diagnosis based on questionnaire or a single interview impracticable, since diagnosis requires a medically-informed appraisal of all the available evidence. For this reason, many of the major psychiatric epidemiological studies - such as the Epidemiological Catchment Area studies (Robins et al. 1984), the US National Co-morbidity Survey (Kessler et al. 1994) and the British Psychiatric Morbidity Survey (Jenkins et al. 1997)-make no attempt to identify hysteria.

Thirdly, epidemiology is by definition the study of illness in populations, and yet many hospitalbased services (and it is here that most hysteria is diagnosed and studied) struggle to define the population from which they draw their cases, because so few hospitals have rigorously-defined catchment areas. Population-based surveys could solve this problem but they are expensive and impractical to undertake on the scale necessary, because of the need for medical expertise in making the diagnosis.

\section{WHAT WE KNOW (RATHER THAN WHAT WE THINK WE KNOW) ABOUT THE FREQUENCY OF HYSTERIA}

The result of all these difficulties is that we have a rather hazy view of the epidemiology of hysteria. But that is not the same as saying that we know nothing. A recent systematic review of the literature has identified five studies from which an annual incidence in a defined population can be estimated (Akagi \& House, 2001). One was based on case register data in two countries (Stefànsson et al. 1976) and another on general practice surveys (Watts et al. 1964). Incidence rates can also be deduced from the reports of two neurological practices (Stevens, 1989; Binzer et al. 1997) and a psychiatric one (Karasu et al. 1977). In spite of the variety of methods used, these studies yield rather similar incidence rates, with only one substantially outside the range 5-12 per 100000 per annum. The rate deduced from contacts in psychiatric practice was much lower than the others, which seems to confirm that psychiatrists see only a small proportion of cases.

Community prevalences vary much more widely, in part due to the data referring to different time periods, from near lifetime prevalence (Helgason, 1964) through period prevalences (Nandi et al. 1980; Faravelli et al. 1997), to two studies of point prevalence in general practice (Watts et al. 1964; Singh \& Lee, 1997). Diagnostic criteria were less clear than in the incidence studies, and undoubtedly the higher prevalences are obtained by including cases of somatoform disorder. The lowest prevalence figures suggest a rate of about 50 per 100000 for cases of conversion disorder known to health services at any one time, with perhaps twice that number affected over a 1 year period. Though none of these studies is perfect, they suggest a burden of disability associated with chronic hysteria that is far higher than a typical practising psychiatrist might suspect, or than is reflected in standard textbooks of psychiatry or clinical psychology.

As to the evidence for a change in the rate of the illness over time, the review found six studies (Stephens \& Kamp, 1962; Anstee, 1972 b; Stefanis et al. 1976; Wig et al. 1978; Trimble, 1981; Nandi et al. 1992) that have documented rates in one place on more than one occasion. These studies generally do not support the belief that the illness is disappearing in the Western countries. In fact it is quite difficult to identify the evidence there ever was for such a belief, which seems to be based mainly upon impressions from clinical practice. It is worth noting that Charcot described only 89 patients with hysteria in his professional lifetime (Micale, 1990), so any clinician who thinks he or 
she is not seeing many cases might reflect that even the Master was not kept that busy with the condition.

\section{WHY WE NEED A BETTER EPIDEMIOLOGY THAN WE HAVE}

The literature suggests that hysteria is not a rare condition (it has apparently a similar incidence to schizophrenia) although it may not commonly come to the attention of psychiatrists outside liaison psychiatry. But the figures must be regarded as unreliable. Only one study (Faravelli et al. 1997) met all the required quality criteria - a standardized case definition, systematic case ascertainment and a clear definition of the population denominator - and its estimated point prevalence was based on two cases identified from a community sample of 673 people.

Many studies document the rate of hysterical conversion in patients presenting to out-patient and in-patient hospital services. Not surprisingly, rates are lowest in studies among unselected general hospital patients $(0 \cdot 02-0 \cdot 12 \%)$ (Folks et al. 1984; Tomasson et al. 1991) and attenders in the accident and emergency department (0.01-0.21\%) (Dula and DeNaples, 1995; Anstee, 1972a). The rate is an order higher among patients presenting to neurological services (1-10\%) as one might expect. Great disparities in rates found in different clinical settings indicate the selection biases which can distort results in hysteria research. We still know little about the causes or outcome of hysteria, and yet all the available research is based on such clinical populations. One resulting bias will be under-representation of acute or transient cases. Research concentrating on chronic cases will not address important issues such as reasons for acute onset or rapid improvement. Prognostic studies which exclude new transient cases will inevitably give a distorted picture of the natural history of a disorder and yet there is no true inception cohort study in the literature.

There are few randomized controlled trails in hysteria. The Cochrane Library lists only two: one compares electrosleep with relaxation (Scallet et al. 1976), and the other describes the effect of hypnosis in eight patients (Moene et al. 1998). Clearly, if hysteria is anything like as common as the literature suggests, then we need more evidence about effective treatments. The design of clinical trials will need evidence on incidence (to plan recruitment) and outcomes (to plan sample size) and is therefore crucially dependent upon good epidemiology.

Our conclusion must be that the epidemiology of hysteria has been neglected. The disorder has vanished only in the sense that it has become invisible to psychiatrists as a subject for research. We are in need of new studies using rigorous methods, if we are to develop a better understanding of the condition or to evaluate candidates for its treatment.

HIROKO AKAGI AND ALLAN HOUSE

\section{REFERENCES}

Akagi, H. \& House, A. (2001). The epidemiology of hysterical conversion. In Contemporary Approaches to the Science of Hysteria: Clinical and Theoretical Perspectives (ed. P. Halligan, C. Bass and J. Marshall), pp. 73-87. Oxford University Press: Oxford.

American Psychiatric Association (1994). Diagnostic and Statistical Manual of Mental Disorders 4th edn. American Psychiatric Association: Washington, DC.

Anstee, B. H. (1972b). Psychiatry in the casualty department. British Journal of Psychiatry 120, 631-634.

Anstee, B. H. (1972a). The pattern of psychiatric referrals in a general hospital. British Journal of Psychiatry 120, 625-629.

Binzer, M., Andersen, P. M. \& Kullgren, G. (1997). Clinical characteristics of patients with motor disability due to conversion disorder: a prospective control group study. Journal of Neurology, Neurosurgery and Psychiatry 63, 83-88.

BMJ (1976). The search for a psychiatric Esperanto. British Medical Journal ii, 59-60.

Brownsberger, C. N. (1966). Hysteria: a common phenomenon? American Journal of Psychiatry 123, 110.
Dula, D. J. \& DeNaples, L. (1995). Emergency department presentation of patients with conversion disorder. Academic Emergency Medicine 2, 120-123.

Faravelli, C., Salvatori, S., Galassi, F., Aiazzi, L., Drei, C. \& Cabras, P. (1997). Epidemiology of somatoform disorders: a community survey in Florence. Social Psychiatry and Psychiatric Epidemiology 32, 24-29.

Folks, D. G., Ford, C. V. \& Regan, W. M. (1984). Conversion symptoms in a general hospital. Psychosomatics 25, 285-289; 291; 294-295.

Helgasson, T. (1964). Epidemiology of mental disorders in Iceland - a psychiatric and demographic investigation of 5395 Icelanders. Acta Psychiatrica Scandinavia Suppl. 173.

Jenkins, R., Bebbington, P., Brugha, T., Farrell, M., Gill, B., Lewis, G., Meltzer, H. \& Pettigrew, M. (1997). The national psychiatric morbidity surveys of Great Britain-strategy and methods. Psychological Medicine 27, 765-774.

Karasu, T. B., Plutchik, R., Steinmuller, R. I., Conte, H. \& Siegel, B. (1977). Patterns of psychiatric consultation in a general hospital. Hospital and Community Psychiatry 28, 291-294.

Kessler, R. C., McGonagle, K. A., Zhao, S., Nelson, C. B., Hughes, M., Eshleman, S., Wittchen, H.-U. \& Kendler, K. S. (1994). 
Lifetime and 12-month prevalence of DSM-III-R psychiatric disorders in the United States. Archives of General Psychiatry 51 8-19.

Micale, M. S. (1990). Hysteria and its historiography: the future perspective. History of Psychiatry 1, 33-124.

Micale, M. S. (1993). On the 'disappearance' of hysteria: a study in the clinical decontruction of an illness. Isis 84, 496-526.

Moene, F. C., Hoogduin, K. A. \& Van Dyck, R. (1998). The inpatient treatment of patients suffering from (motor) conversion symptoms: a description of 8 cases. International Journal of Clinical and Experimental Hypnosis 46, 171-90.

Nandi, D. N., Mukherjee, S. P., Boral, G. C., Banerjee, G., Ghosh, A., Sarkear, S. \& Ajmany, S. (1980). Socio-economic status and mental morbidity in certain tribes and castes in India - a crosscultural study. British Journal of Psychiatry 136, 73-85.

Nandi, D. N., Banerjee, G., Nandi, S. \& Nandi, P. (1992). Is hysteria on the wane? A community survey in West Bengal. British Journal of Psychiatry 160, 87-91.

Neugebauer, R., Dohrenwend, B. P. \& Dohrenwend, B. S. (1980). Formulation of hypotheses about the true prevalence of functional psychiatric disorders among adults in the United States. In Mental Illness in the United States (ed. B. Dohrenwend), pp. 45-94. Praeger: New York.

Robins, L. N., Heizer, J. E., Weissman, M. M., Orvaschel, H., Gruenberg, E., Burke, J. D. \& Regier, D. A. (1984). Lifetime prevalence of specific psychiatric disorders in three sites. Archives of General Psychiatry 41, 949-958.

Satowa, R. (1979). Where has all the hysteria gone? Psychoanalytic Review 66, 463-477.

Scallet, A., Cloninger, C. R. \& Othmer, E. (1976). The management of chronic hysteria: a review and double-blind trial of electrosleep and other relaxation methods. Diseases of the Nervous System 37, $347-53$.

Shorter Oxford English Dictionary, 3rd edn. (1972). Oxford University Press: Oxford.
Singh, S. \& Lee, A. S. (1997). Conversion disorders in Nottingham: alive but not kicking. Journal of Psychosomatic Research 43, 425-430.

Stefanis, C., Markidis, M. \& Christodoulou, G. (1976). Observations on the evolution of hysterical symptomatology. British Journal of Psychiatry 128, 269-275.

Stefänsson, J. G., Messina, J. A. \& Meyerowitz, S. (1976). Hysterical neurosis, conversion type: clinical and epidemiological considerations. Acta Psychiatrica Scandinavia 53, 119-138.

Stephens, J. H. \& Kamp, M. (1962). On some aspects of hysteria: a clinical study. Journal of Nervous and Mental Diseases 134 305-315.

Stevens, D. (1989). Neurology in Glouscestershire: the clinical workload of an English neurologist. Journal of Neurology, Neurosurgery and Psychiatry 52, 439-446.

Tomasson, K., Kent, D. \& Coryell, W. (1991). Somatization and conversion disorders: comorbidity and demographics at presentation. Acta Psychiatrica Scandinavia 84, 188-193.

Trimble, M. R. (1981). Liaison psychiatry with special reference to neurological units. In Neuropsychiatry, pp. 70-90. John Wiley \& Sons: Chichester.

Veith, I. (1965). Hysteria. The History of a Disease. University of Chicago Press: Chicago.

Watts, C. A. H., Cawte, E. C. \& Kuenssberg, E. V. (1964). Survey of mental illness in general practice. British Medical Journal 2, 1351-1359.

Wessely, S. (2001). Discrepancies between diagnostic criteria and clinical practice. In Contemporary Approaches to the Science of Hysteria: Clinical and Theoretical Perspectives (ed. P. Halligan, C. Bass and J. Marshall), pp. 63-72. Oxford University Press: Oxford

Wig, N. N., Varma, V. K. \& Khanna, B. C. (1978). Diagnostic characteristics of a general hospital adult outpatients' clinic. Indian Journal of Psychiatry 20, 262-266.

World Health Organization (1992). The ICD-10 Classification of Mental and Behavioural Disorders. World Health Organization: Geneva 